Article

\title{
Fermentation dynamics of Ethiopian traditional beer (tella) as influenced by substitution of gesho (Rhamnus prinoides) with Moringa stenopetala as innovation for nutrition
}

\author{
Ajanw Maru Birhanu ${ }^{1}$, Tadesse Fikre Teferra ${ }^{2,}$ * and Tesfu Bekele lema ${ }^{2}$ \\ 1 Nifas Silk Polytechnic College, Addis Ababa, Ethiopia; ajanawmaru2011@gmail.com \\ 2 School of Nutrition, Food Science and Technology, Hawassa University, Ethiopia; ethiotesfea@gmail.com \\ * Correspondence: tadessefikre@gmail.com; Tel.: +251994166545
}

\begin{abstract}
This study was designed to improve Ethiopian traditional beer - tella with the substitution of gesho by moringa leaves to enhance micronutrients. Substation of gesho by moringa from 50 $100 \%$ against the biochemical dynamics, nutritional and sensorial profiles of tella was assessed. Incorporation of moringa suppressed the activities of yeast and favored that of lactic acid bacteria, which shifted the property of the product from mild alcoholic nature to low alcoholic and mild acidic nature, revealing the probiotic potential of tella. Moringa leaves at $100 \%$ substitution for gesho resulted in to the least yeast count compared to the other formulations. The storage of tella samples over periods of 10 days also strengthened the probiotic nature of tella by drastically reducing the yeast cell counts (from 5 logs to $<1$ ). This corresponded to the slow increase in the acidity $(0.63$ to $0.99 \%$ ), indicating comparatively higher activities of lactic acid bacteria. The best nutritional contents (dietary minerals) and sensorial acceptance of the product was attained at the $50 \%$ substitution of gesho by moringa. The implication of the present study is that ethnic foods and beverages can be innovated to meet the nutritional needs of the community
\end{abstract}

Keywords: Ethnic beer, borde, shamita, keribo, korefe, indigenous drinks, fermented beverages, probiotics, Farsoo, moringa

\section{Introduction}

Tella is an Ethiopian traditional fermented beer-like beverage made from varieties of cereals and a herb locally called gesho (Rhamnus prinoides). Tella resembles commercial beer in that it is made of malted barley and other grains, with the addition of gesho as a traditional beer [1]. Tella is a predominant traditional alcoholic drink consumed in almost every region of Ethiopia, but more popular in the central and northern parts of the country [2]. A variant of tella known as karibo, which is made without the addition of the herb gesho and brief fermentation, is also common among the Muslim families in Ethiopia [3]. Tella is still widely consumed on special occasions like holidays and wedding ceremonies in the urban areas. It is part of staple foods of the rural families during the busy farming seasons as a refreshing and energy drinks among the rural communities. Tella is known by different names among the Ethnic groups in Ethiopia, which includes an (tella) in Amharic, Farsoo in Afaan Oromoo and Siwa in Tigrigna. There are also variations in the ingredients and processes of tella making among the different ethnic cultures in Ethiopia [4]. Ingredients and processing methods used by the Amhara mothers in the north-western Ethiopia is more common and considered for the current work. With the popularization of industrial beer and soft drinks, consumption of tella and other traditional beverages is declining. Moreover, a stigmatized view towards tella consumption is developing among the urban youth.

Tella is a low alcoholic beverage with a maximum alcoholic level of $\sim 4.0 \% \mathrm{~g} / 100 \mathrm{~mL}$ [5], which makes nutritionally important in the rural community. Tella also makes up a 
livelihood of significant number of poor women in a petty trade setting [5]. It is therefore, important to investigate the processes, properties and ingredients of such traditional products to improve it and scale to a mechanized commercial processing level. Fermented indigenous foods and beverages are also being subjects of extensive research for popularizations due to potential roles of involved microbes for probiotics in search for functional foods. There are recent reports of some positive outcomes of the Ethiopian traditionally fermented foods and beverages [6,7].

There is therefore, an obvious need to improve the nutritional properties of the traditional beverages in line with their likely of commercialization in the local and international markets. Looking of more nutritious and cheaper ingredients that can serve multiple purposes is of great importance. In line with this, the current research was designed to substitute gesho (R. prinoides) with Moringa stenopetala, which is reported to have higher concentrations and diversity of micronutrients among herbs used as foods [8-10], which is sometimes called the "miraculous African tree" [8]. Leave powder of M. stenopetala was used to substitute $50-100 \%$ of the traditionally used herb - gesho (R. prinoides) with both the kitta (barley made into a thick flat bread) and Enkuro (roasted barley flour made into a cake of water and flour) based preparations. Comparisons of microbial activities and physicochemical characteristics at different phases fermentation were made to a control tella. Comparisons of selected micronutrient - dietary minerals at the end of fermentation were carried out.

\section{Materials and Methods}

\subsection{Ingredients}

The basic raw materials for tella preparation raw grain barley (Hordeum vulgare), barley malt; leaves and steams of gesho (R. prinoides) were obtained and prepared in Motta town of Gojjam, Amhara Region, Ethiopia with the help of experienced local women in traditional tella brewing. Moringa (M. stenopetala) leaf powder was purchased from local supermarket in Hawassa city, Ethiopia. The ingredients were packaged in polyethylene bags and stored under cold and dry condition until used in further preparation steps.

\subsection{Preparation of Ingredients}

Barley grain was cleaned and roasted to dark color for modification of the endosperm and flavor and color development. The roasted barley grain was then milled into flour (locally known as derekot) and packaged into polyethylene bags and stored at room temperature until required for the next processing steps. Barley malt was cleaned and milled and preserved the same way the derekot was stored. The leaves and thin branches of gesho were pounded of a desirable particle size (not too fine), using a wooden traditional mortar and pestle. The powders were also packaged in polyethylene bags and stored at dry and dark place until required for the next step of tella making. The moringa leaf powder was also stored under the same conditions with gesho.

\subsection{Adjunct Preparation Methods for Tella}

Tella was made using two commonly used traditional methods: kitta and emkuro based preparations. The roasted barley flour was mixed with adequate water to make sticky dough in the kitta preparations, that was baked into thick flat bread on a hot metallic griddle [11]. Kitta was kept to cool and broken into pieces. Kitta pieces were dried and preserved for use in the difdif stage of tella fermentation. For the enkuro based preparations, the roasted barley powder was mixed with limited amount of water (compared to that of kitta) and kneaded into bolus cakes, that was cooked on a hot metallic griddle. Enkuro was then cooled, dried, packaged in polyethylene bag and transported to the laboratory for use in the difdif stage of tella fermentation.

\subsection{Tella Processing Phases}


Tella processing employs three basic fermentation stages: namely tejet, tenses and difedef $[1,12]$. Three types of tejet were made by mixing $100 \mathrm{~g}$ of malt and $125 \mathrm{~g}$ of (i) gesho leaf powders (ii) moringa leaf powders (iii) 50:50 gesho - moringa mixtures and left to ferment for 96 hrs. being covered with a piece of clean cloth. The tejet preparations were devided into two and converted to tenses by adding $225 \mathrm{~g}$ of either kitta or enkuro adjuncts (section 2.3). The tenses preparations were also left covered to ferment for another 96 hrs. The fermented tenses was transformed into the final stage of tella fermentation, the difdif by adding $900 \mathrm{~g}$ of the remaining adjuncts (kitta and enkuro) and diluted to tella with 5 liters of water. The final tella mixture was also left covered for another 96 hrs. of fermentation. The solution strained with clean muslin cloth to remove suspended impurities and biochemically and sensorially characterized.

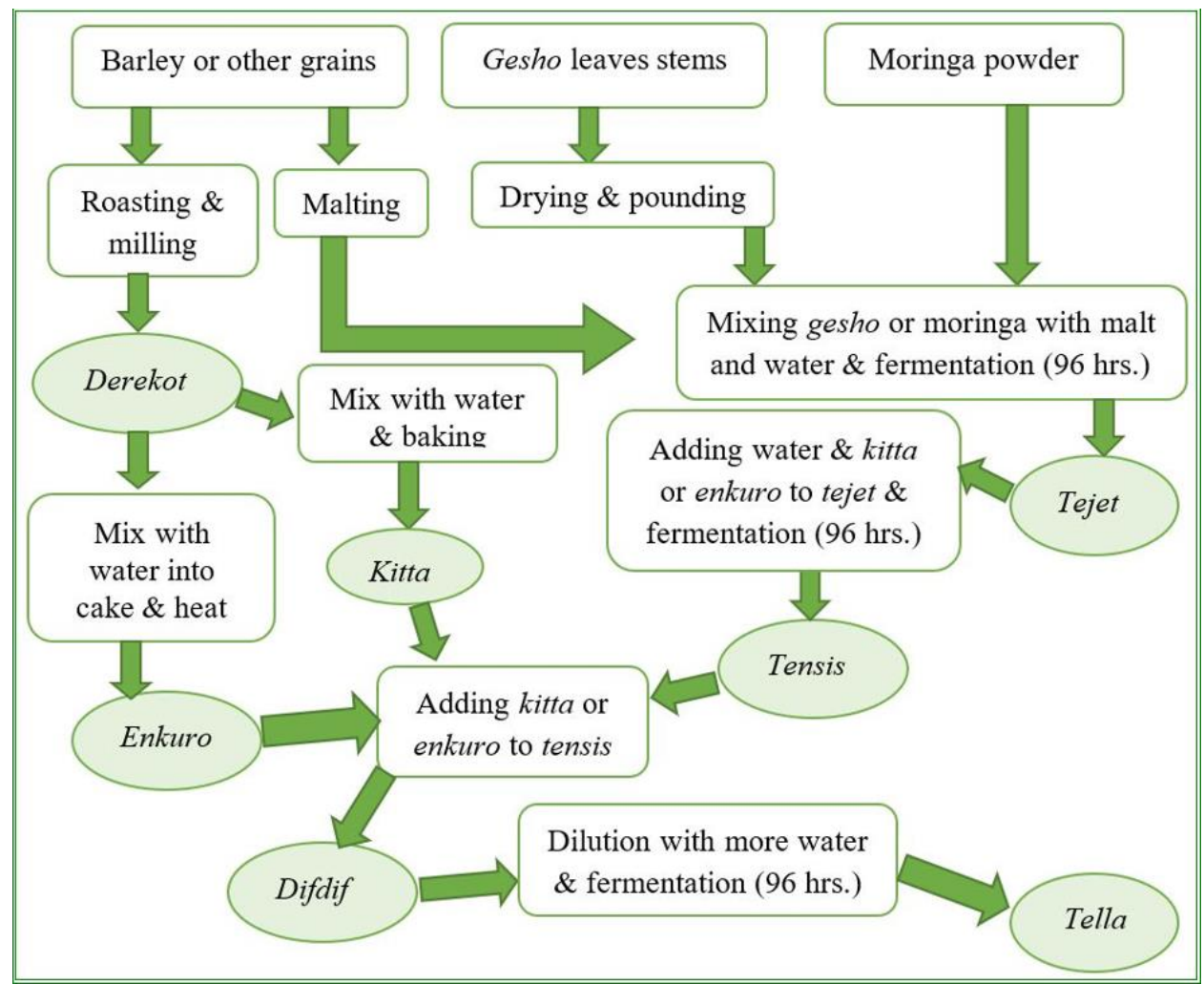

Figure 1. Flow diagram for tella making depicting the major ingredients and operations

\subsection{Determination of Biochemical Dynamics during Tella Fermentation}

\subsubsection{Yeast Counts}

Ten $\mathrm{g}$ of samples at tejet, tenses and tella stages were weighed into a stomacher bag (Lab-Blender 400, Seward Medical, London, England) with $90 \mathrm{~mL}$ sterile $0.1 \%$ peptone water (Merck) and homogenized for $30 \mathrm{~s}$. The homogenized samples were prepared into dilutions with peptone water and $0.1 \mathrm{~mL}$ of each sample were spread-plated in triplicates on pre-dried plates of yeast extracts glucose chloramphenicol (YGC) agar and incubated at $28^{\circ} \mathrm{C}$ for 5 days [13].

\subsubsection{Total Aerobic Mesophilic Counts (TAMC)}

Samples (10 g) of tejet, tenses and tella were transferred into a stomacher with $90 \mathrm{~mL}$ sterile $0.1 \%$ peptone water and homogenized for $30 \mathrm{~s}$. The homogenate was separately $(0.1$ $\mathrm{mL}$ ) spread-plated in triplicates on pre-dried plate count agar (PCA) and incubated at $30^{\circ} \mathrm{C}$ for 48 hrs. The total aerobic mesophilic count (TAMC) were enumerated and averages microbial loads were reported as log10 colony forming units (CFU) per mL of samples [14].

2.5.3. Lactic Acid Bacteria (LAB) 
Similar dilution and homogenization protocols to those used for TAMC was employed. LAB from the different preparation and formulations were inoculated on Man, Rogosa and Sharpe (MRS) agar plates and anaerobically incubated at $30^{\circ} \mathrm{C}$ for $72 \mathrm{hrs}$. The LAB CFU were counted and reported in similar form for TAMC (section 2.5.3.).

\subsubsection{Enterobacteriaceae}

\subsection{Determination of Physicochemical Properties of Tella}

\subsubsection{Determination of $\mathrm{pH}$}

The $\mathrm{pH}$ of fermented tella using a digital $\mathrm{pH}$ meter. About $10 \mathrm{~g}$ of the different samples were weighed in duplicates in $250 \mathrm{~mL}$ beaker and mixed with $20 \mathrm{~mL}$ of distilled water. The mixes were stirred for $10 \mathrm{~min}$ and the measurements were taken after calibrating the meter with buffers of known $\mathrm{pH}$ (4.0 and 7.0). The rode of the $\mathrm{pH}$ meters was thoroughly washed using distilled water in between samples.

\subsubsection{Alcohol Content}

The specific gravity of the samples from different preparation and formulations were measured using a hydrometer. The alcohol percent by volume (ABV (\%)) was estimated by a standard conversion factors based on Association of Official Agricultural Chemists (AOAC and American Society of Brewing Chemists (ASBC) $[15,16]$.

\subsubsection{Titratable Acidity}

Titratable acidity (also called total acidity) measures the total acid concentration in a food. This quantity is determined by exhaustive titration of intrinsic acids with a standard base. Titratable acidity (TA) was determined by titrating $10 \mathrm{~g}$ of samples with $0.1 \mathrm{~N} \mathrm{NaOH}$ using three drops of phenolphthalein as indicator. Titratable acidity of tella samples was expressed as a percentage of lactic acid [13], given by:

$$
\mathrm{TA}(\%)=\text { volume of } \mathrm{NaOH} \times 0.0
$$

\subsubsection{Color}

The color of each tella sample was determined using a spectrophotometer (Jenway model 7315, Bibby Scientific, Stone, UK), set at $430 \mathrm{~nm}$. The spectrophotometer was set up in concentration mode to directly calculate the European Brewery Convention (EBC) value directly.

\subsubsection{Turbidity}

Turbidity of each sample was determined by Haze meter based on the percentage of light deflected from the incoming light direction based on the European Brewery Convention (EBC) and ASBC methodologies. Unfiltered beer sample was poured into a test bottle and a calibrated turbidity meter was used to monitor the turbidity (WGZ-4000, Xinrui, China) [17].

\subsection{Tella Nutrient Analysis}

Dietary mineral contents of tella were analyzed see if addition of moringa improved the dietary minerals. The digestates were refluxed for 90 minutes until clear solution was obtained. Dietary minerals including iron, calcium, magnesium, potassium, sodium, and zinc were analyzed using flame atomic absorption spectrophotometer. Samples $(10 \mathrm{~mL})$ were digested in $2 \mathrm{~mL}$ of nitric acid and $2 \mathrm{~mL}$ of hydrogen peroxide. Estimation of the minerals were made using the spectrophotometer at specific wavelengths for each element.

\subsection{Sensory Acceptability of Tella}

A consumer sensory test was used to assess the difference between sensory acceptability of tella from different formulations (gesho versus moringa) under different adjunct preparation methods. Sensory attributes considered included color, aroma, taste and overall acceptability. Adults $(\mathrm{n}=46)$ who normally consume tella, were recruited and 
oriented to score the level of liking or disliking the products based on the 5-point hedonic scale, where 5 = like extremely, 4 = like slightly, $3=$ neither like nor dislike, 2 = dislike slightly and 1 = dislike extremely. The panelists have been instructed to cleanse their palates before and between samples. Tella samples were coded with random three-digit numbers and presented to panelists at random orders.

\subsection{Experimental Design and Data Analysis}

The experiment was designed into a $2 \times 3 \times 3$ factorial arrangement for the biochemical properties, where 2 levels of adjunct preparation (kitta versus enkuro), 3 levels of formulations (100\% gesho, 50\% and 100\% moringa substitutions) and 3 stages of fermentation (tejet, tenses and difdif) were compared. Similarly, a 2x3 factorial with 2 levels of preparations and 3 formulations for the dietary minerals and with an additional 3 levels of storage days (1, 5 and 10) were compared using analysis of variance (ANOVA) followed by Tukey's honestly significant (HSD) mean separation techniques. Data were presented in graphs (main effects) and Tables (interaction) in the form of least square means with standard errors.

\section{Results}

\subsection{Biochemical Dynamics by Fermentation Stages}

\subsubsection{Microbial and Biochemical Dynamics}

The microbial loads (LAB, TAMC, yeast) and chemical status ( $\mathrm{pH}$. TA) are by the formulations and fermentation stages (Figure 1, Table 1). The adjunct preparation method (kitta versus enkuro, Figure 1 [A]) did not seem to influence majority of the biochemical parameters except the for the titratable acidity (TA, \%). The kitta preparation method resulted in higher acid production, which might be due to the differences in the degrees of heating and starch modification. The substitution of gesho by moringa favored lactic acid bacteria but limited to growth of yeast (Figure 1 [B]), which paralleled the increasing trends of lactic acid concentrations. The highest yeast growth on the other hand corresponded to the 50:50 gesho-moringa blends and there were no clear trends in the total aerobic mesophilic count (TAMC).

The increasing number of $\log 10 \mathrm{CFU}$ of the LAB together with the substitution levels of moringa ( 0 to $100 \%$ ) was also accompanied with an increasing of lactic acid concentrations. This is evident that the alcohol production suppressed by the addition of moringa leaf powder in stead of the traditionally used gesho. This also implies that substitution of gesho with moringa has better probiotic potential and nutritional relevance. The ranges of the biochemical parameters assessed in the present study for tella are in agreement with those previously reported for tella [5] and keribo [3].

There was no Enterobacteriaceae detected in the tella samples, that indicates low chance of the product being contaminated by poor hygienic practices. The reason might be the high acidity and alcohol levels that create unfavorable conditions for the growth of pathogens. However, it is always recommended that the maximum possible hygienic and sanitary practices are exercised during processing and handling of indigenous foods and beverages to safeguard the safety of the public.

Significantly different microbial loads and chemical phenomena were observed at the different stages of tella fermentation (Figure $1[\mathrm{C}]$, Table 1). The highest LAB and yeast counts were observed at the tenses stage likely due to the addition of the adjunct regardless of its type (kitta or enkuro). However, the $\mathrm{pH}$ continued to drop as the three stages of fermentation (tejet through difdif), which also twinned the continuously accumulating lactic. The declining counts of bacteria (particularly the TAMC) and yeas in the difdif phase of fermentation attributed to the depletion of nutrients and acidifying environment. This presents a probiotic application opportunity as tella is consumed without heating after fermentation. 

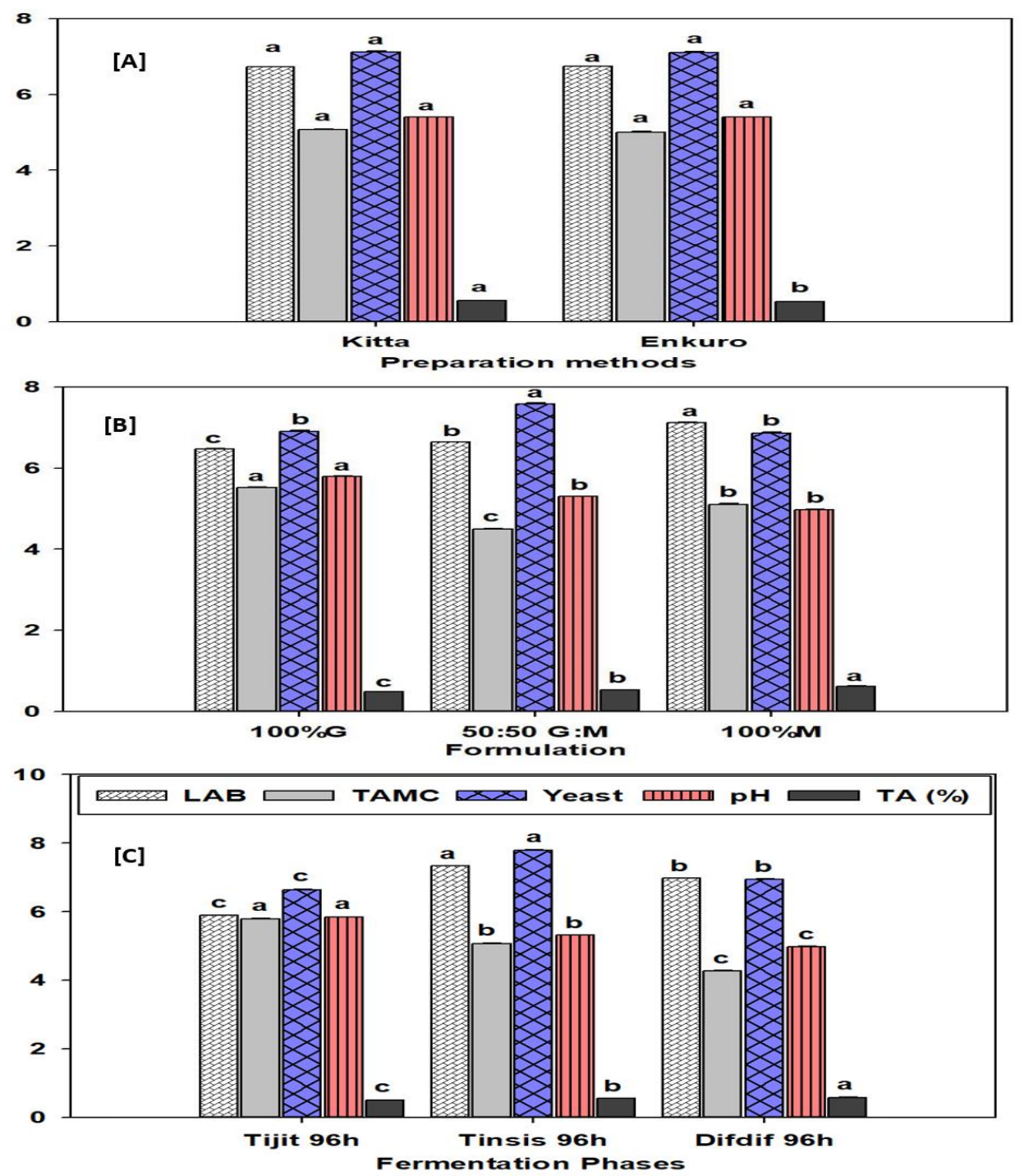

Figure 2. Biochemical properties of Tella for different Preparations [A], Formulations [B] and Fermentation phases $[\mathrm{C}] ; \mathrm{LAB}=$ Lactic acid bacteria; $\mathrm{TAMC}=$ total aerobic mesophilic count; $\mathrm{TA}=$ titratable acidity; $\mathrm{G}=$ Gesho; $\mathrm{M}=$ moringa; values are least square means with standard error as error bars and bars with different letters are significantly different $(\mathrm{p}<0.05)$.

Table 1. Biochemical properties of tella samples as influenced by combined effects of formulation and fermentation phases

\begin{tabular}{|c|c|c|c|c|c|}
\hline Variables & $\begin{array}{c}\text { LAB (Log10 } \\
\text { CFU/mL) }\end{array}$ & $\begin{array}{c}\text { TAMC } \\
\text { (Log10 } \\
\text { CFU/mL) }\end{array}$ & $\begin{array}{c}\text { YEAST } \\
\text { (Log10 } \\
\text { CFU/mL) }\end{array}$ & $\mathrm{pH}$ & TA \\
\hline \multicolumn{6}{|c|}{ Preparations by formulations } \\
\hline Kitta, $100 \% G$ & $6.47 \mathrm{c}$ & $5.56^{\mathrm{a}}$ & $6.93^{b}$ & $5.86^{\mathrm{a}}$ & $0.50^{\mathrm{d}}$ \\
\hline Kitta, 50:50 G:M & $6.62^{b}$ & $4.49^{d}$ & $7.60^{\mathrm{a}}$ & $5.31^{c}$ & $0.54^{c}$ \\
\hline Kitta, $100 \% \mathrm{M}$ & $7.12^{\mathrm{a}}$ & $5.17^{b}$ & $6.87^{b}$ & $4.98^{\mathrm{d}}$ & $0.64^{\mathrm{a}}$ \\
\hline Enkuro, $100 \% G$ & $6.50^{c}$ & $5.48^{a}$ & $6.88^{a}$ & $5.80^{\mathrm{b}}$ & $0.47 \mathrm{e}$ \\
\hline $\begin{array}{c}\text { Enkuro, 50:50 } \\
\text { G:M }\end{array}$ & $6.60^{b}$ & $4.50^{\mathrm{d}}$ & $7.58^{a}$ & $5.31^{\mathrm{c}}$ & $0.50^{c}$ \\
\hline Enkuro, $100 \% \mathrm{M}$ & $7.13^{\mathrm{a}}$ & $5.06^{c}$ & $6.87^{b}$ & $4.98^{\mathrm{d}}$ & $0.60^{b}$ \\
\hline SE & 0.0079 & 0.025 & 0.038 & 0.0086 & 0.0058 \\
\hline \multicolumn{6}{|c|}{ Formulation by phase } \\
\hline $100 \% G$, Tijit $96 \mathrm{~h}$ & $5.30 \mathrm{~g}$ & $6.66^{a}$ & $6.55^{c}$ & $6.20^{a}$ & $0.47 \mathrm{~g}$ \\
\hline
\end{tabular}




\begin{tabular}{|c|c|c|c|c|c|}
\hline $100 \% \mathrm{G}$, Tinsis $96 \mathrm{~h}$ & $7.30^{b}$ & $5.01^{\mathrm{d}}$ & $7.40^{b}$ & $5.80^{b}$ & $0.49 \mathrm{fg}$ \\
\hline $100 \% G$, Difdif $96 h$ & $6.85^{\mathrm{e}}$ & $4.89 \mathrm{~d}$ & $6.78^{c}$ & $5.60^{c}$ & $0.50^{\text {ef }}$ \\
\hline $\begin{array}{c}\text { 50:50 G:M, Tijit } \\
96 \mathrm{~h}\end{array}$ & $5.50^{f}$ & $5.28^{c}$ & $6.63^{c}$ & $5.73^{\mathrm{b}}$ & $0.51^{\text {def }}$ \\
\hline $\begin{array}{c}\text { 50:50 G:M, Tinsis } \\
96 \mathrm{~h}\end{array}$ & $7.41^{\mathrm{a}}$ & $4.86^{\mathrm{d}}$ & $8.80^{a}$ & $5.50^{d}$ & $0.53^{\text {cde }}$ \\
\hline $\begin{array}{c}\text { 50:50 G:M, Difdif } \\
96 \mathrm{~h}\end{array}$ & $6.92^{\mathrm{d}}$ & $3.35^{\mathrm{f}}$ & $7.35^{b}$ & $4.74^{\mathrm{e}}$ & $0.56^{c}$ \\
\hline 100\%M, Tijit 96h & $6.91^{\mathrm{d}}$ & $5.43^{b}$ & $6.73^{c}$ & $5.60^{c}$ & $0.50^{\text {cde }}$ \\
\hline $\begin{array}{c}100 \% \mathrm{M}, \text { Tinsis } \\
96 \mathrm{~h}\end{array}$ & $7.32^{b}$ & $5.35 \mathrm{bc}$ & $7.18^{b}$ & $4.70 \mathrm{e}$ & $0.60^{b}$ \\
\hline $\begin{array}{c}100 \% \mathrm{M}, \text { Difdif } \\
96 \mathrm{~h}\end{array}$ & $7.15^{c}$ & $4.56^{\mathrm{e}}$ & $6.7^{c}$ & $4.59^{f}$ & $0.69^{a}$ \\
\hline SE & 0.0097 & 0.031 & 0.047 & 011 & 0071 \\
\hline
\end{tabular}

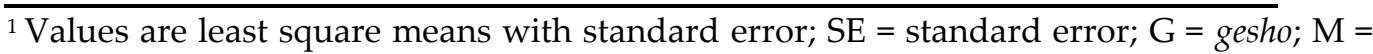
moringa

\subsubsection{Yeast and Biochemical Changes over Storage}

The biochemical changes in tella from the different preparations and formulations was significantly changing over storage period for up to 10 days (Figure 3, Table 2). There was no influence of the preparation methods on the on the yeast cells, $\mathrm{pH}$ and TA levels (Figure $3[\mathrm{~A}]$ ). However, the formulation and storage days after the $96 \mathrm{hrs}$. fermentation, significantly influenced the yeast count, $\mathrm{pH}$ and $\mathrm{TA}$ of the tella samples singly (Figure 3 $[\mathrm{B} \& \mathrm{C}]$ ) and in combination (Table 2). The yeast count showed a drastic decline between the 5 and 10 days of storage, which corresponded to the decrease in the $\mathrm{pH}$ and increasing acidity. 

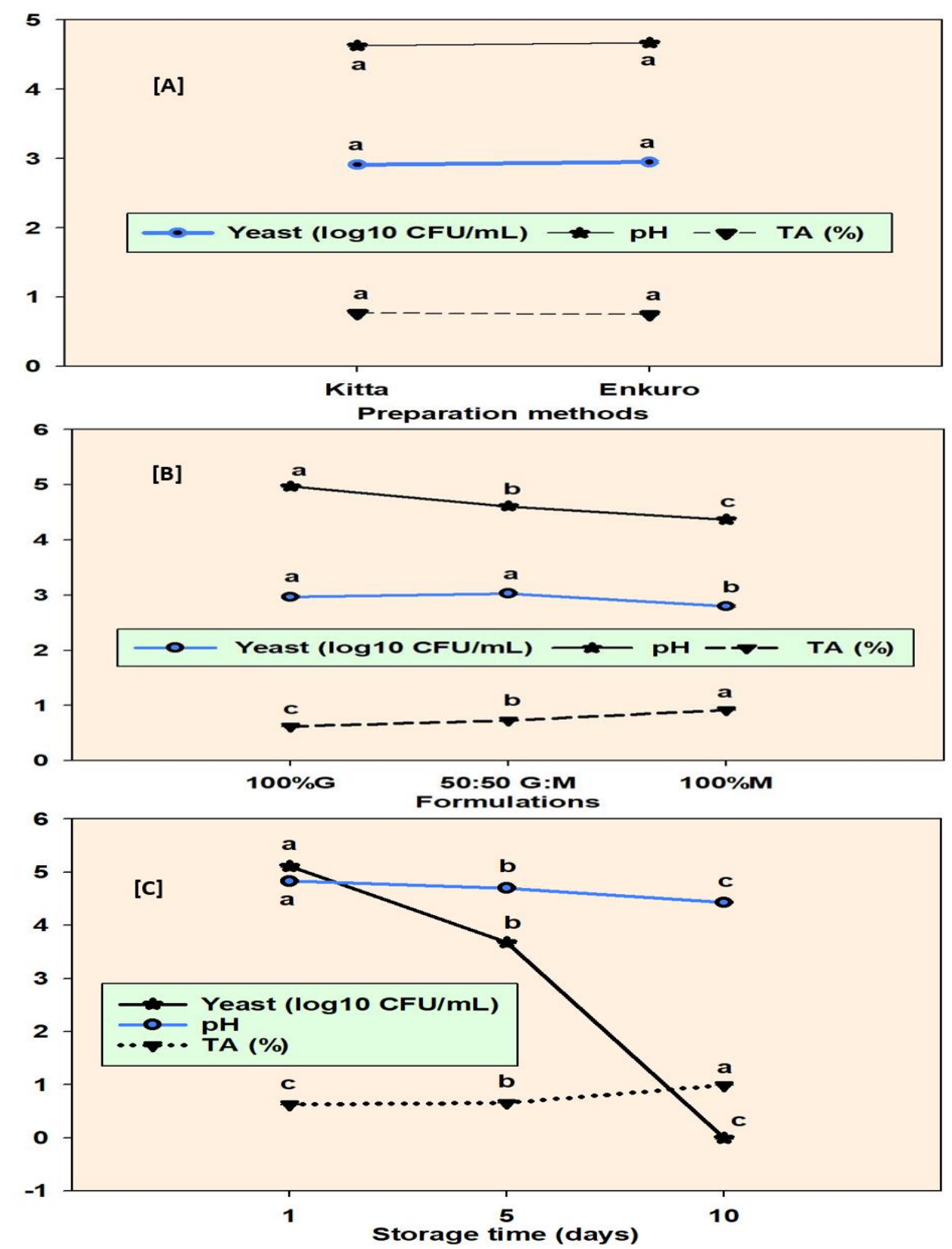

Figure 3. Shelf life of tella for different preparation methods [A], formulations [B] and storage time $[\mathrm{C}] ; \mathrm{TA}=$ Titratable acidity; $\mathrm{G}=$ gesho; $\mathrm{M}=$ moringa; $\mathrm{CFU}=$ colony forming units; values are least square means with standard errors as error bars and those with different connecting letters are significantly different $(\mathrm{p}<0.05)$.

Table 2. Shelf life of tella for different preparation methods $[\mathrm{A}]$, formulations $[\mathrm{B}]$ and storage time $[\mathrm{C}] ; \mathrm{TA}=$ Titratable acidity; $\mathrm{G}=$ gesho; $\mathrm{M}=$ moringa; $\mathrm{CFU}=$ colony forming units; values are least square means with standard errors as error bars and those with different connecting letters are significantly different $(\mathrm{p}<0.05)$.

\begin{tabular}{|c|c|c|c|}
\hline Variables & Yeast $(\log 10 \mathrm{CFU} / \mathrm{mL})^{1}$ & $\mathrm{pH}$ & TA \\
\hline \multicolumn{4}{|c|}{ Preparations by formulations } \\
\hline Kitta, 100\%G & $2.98^{\mathrm{ab}}$ & $4.97^{\mathrm{a}}$ & $0.63^{\mathrm{d}}$ \\
\hline Kitta, 50:50 G:M & $3.01^{\mathrm{a}}$ & $4.56^{c}$ & $0.74^{\mathrm{c}}$ \\
\hline Kitta, 100\%M & $2.73^{c}$ & $4.37^{\mathrm{d}}$ & $0.94^{\mathrm{a}}$ \\
\hline Enkuro, $100 \% \mathrm{G}$ & $2.95^{\mathrm{ab}}$ & $4.97^{a}$ & $0.62^{\mathrm{d}}$ \\
\hline Enkuro, 50:50 G:M & $3.05^{\mathrm{a}}$ & $4.67 \mathrm{~b}$ & $0.72^{c}$ \\
\hline Enkuro, $100 \% \mathrm{M}$ & $2.86^{\mathrm{bc}}$ & $4.37^{\mathrm{d}}$ & $0.91^{\mathrm{b}}$ \\
\hline
\end{tabular}




\begin{tabular}{cccc} 
SE & 0.0297 & 0.021 & 0.006 \\
\hline Preparation by storage (days) & & & \\
\hline Kitta, 1 & $5.10^{\mathrm{a}}$ & $4.83^{\mathrm{a}}$ & $0.63^{\mathrm{c}}$ \\
Kitta, 5 & $3.63^{\mathrm{c}}$ & $4.64^{\mathrm{b}}$ & $0.68^{\mathrm{b}}$ \\
Kitta, 10 & $\mathrm{ND}$ & $4.43^{\mathrm{c}}$ & $0.99^{\mathrm{a}}$ \\
Enkuro, 1 & $5.12^{\mathrm{a}}$ & $4.83^{\mathrm{a}}$ & $0.63^{\mathrm{c}}$ \\
Enkuro, 5 & $3.73^{\mathrm{b}}$ & $4.76^{\mathrm{a}}$ & $0.65^{\mathrm{c}}$ \\
Enkuro, 10 & $\mathrm{ND}$ & $4.42^{\mathrm{c}}$ & $0.98^{\mathrm{a}}$ \\
Formulation by storage (days) & & & \\
\hline $100 \% \mathrm{G}, 1$ & $5.23^{\mathrm{a}}$ & $5.31^{\mathrm{a}}$ & $0.54^{\mathrm{e}}$ \\
$100 \% \mathrm{G}, 5$ & $3.68^{\mathrm{d}}$ & $4.99^{\mathrm{b}}$ & $0.55^{\mathrm{e}}$ \\
$100 \% \mathrm{G}, 10$ & $\mathrm{ND}$ & $4.61^{\mathrm{d}}$ & $0.75^{\mathrm{d}}$ \\
$50: 50 \mathrm{G}: \mathrm{M}, 1$ & $5.23^{\mathrm{a}}$ & $4.65^{\mathrm{cd}}$ & $0.59^{\mathrm{e}}$ \\
$50: 50 \mathrm{G}: \mathrm{M}, 5$ & $3.87^{\mathrm{c}}$ & $4.76^{\mathrm{c}}$ & $0.62^{\mathrm{e}}$ \\
$50: 50 \mathrm{G}: \mathrm{M}, 10$ & $\mathrm{ND}$ & $4.44^{\mathrm{ef}}$ & $0.99^{\mathrm{b}}$ \\
$100 \% \mathrm{M}, 1$ & $4.89^{\mathrm{b}}$ & $4.53^{\mathrm{de}}$ & $0.75^{\mathrm{d}}$ \\
$100 \% \mathrm{M}, 5$ & $3.50^{\mathrm{d}}$ & $4.35^{\mathrm{fg}}$ & $0.79^{\mathrm{c}}$ \\
$100 \% \mathrm{M}, 10$ & $\mathrm{ND}$ & $4.23^{\mathrm{g}}$ & $1.23^{\mathrm{a}}$ \\
SE & 0.036 & 0.026 & 0.007 \\
\hline
\end{tabular}

${ }^{1}$ Values are least square means with standard error; $\mathrm{SE}=$ standard error; $\mathrm{ND}=$ not detected; $\mathrm{G}=$ gesho; $\mathrm{M}=$ moringa; values are least square means with standard errors as error bars and those with different connecting letters are significantly different $(\mathrm{p}<0.05)$.

\subsection{Dietary Minerals of Tella from Different Preparations and Formulations}

The main effect of formulation on the dietary mineral contents of tella was statistically meaningful (Figure 4 [B\&D]). There was no significant variation in the mineral levels due to the preparation techniques (kitta versus enkuro). The highest mineral contents were observed for the formulation with the $50 \%$ substitution of gesho with moringa. The second highest levels all assessed minerals (except for $\mathrm{Zn}$ ), were recorded for the $100 \%$ substation of gesho with moringa, indicating that moringa has mineral concentration higher than that of gesho. The increase in concentrations of the $\mathrm{Ca}$ and $\mathrm{Mg}$ minerals in the $50 \%$ substitution of gesho with moringa, was higher than just the summation of the two components, which indicates indicated some sort of synergistic effect of interest. The increased levels of the two minerals more than the sum of the two presents a great nutritional desirability of blended gesho and moringa in tella preparation. The increased levels of $\mathrm{Ca}$ and $\mathrm{Mg}$, opens an interesting research dimension in tella and other Ethnic foods of similar preparations.

Considering the interactions of preparation methods with the formulations, the $\mathrm{Zn}$, $\mathrm{Ca}, \mathrm{Mg}, \mathrm{Na}, \mathrm{K}$ and Fe ranged from (mgL $\left.{ }^{-1}\right) 0.81$ to $1.20,4.76$ to $9.96,3.16$ to $7.21,61.22$ to $120.67,250$ to 320 and 0.008 to 0.030 , respectively (Table 3). The formulation with the $50 \%$ gesho substation with moringa (50:50 gesho - moringa blends) exhibited higher levels of mineral concentrations in a consistent trend regardless of the adjunct preparation (kitta or enkuro). Ca and $\mathrm{Mg}$ concentrations obtained from tella samples in the current work is lower and $\mathrm{K}$ and Na levels were higher than the values reported by Tekle et al. [5]. The difference might be due to the variations in ingredients. 

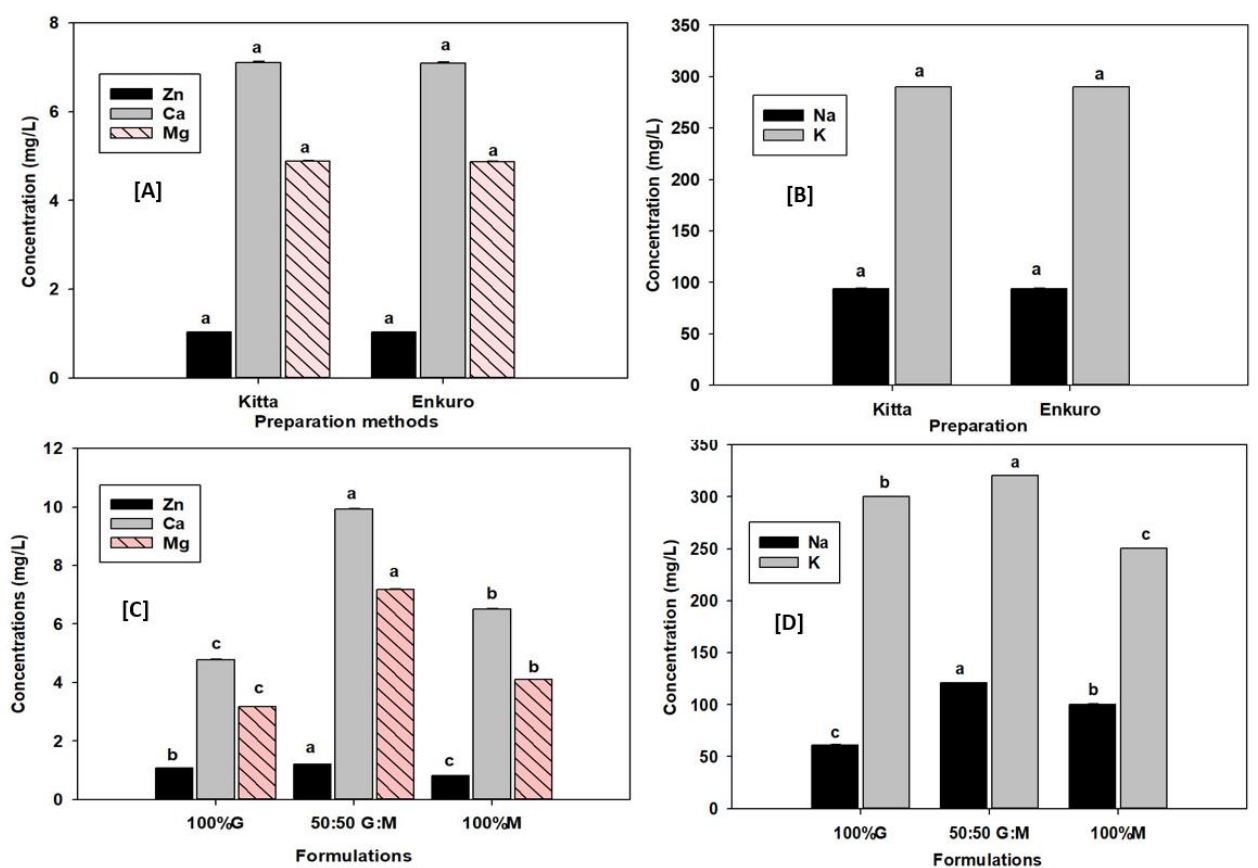

Figure 4. Mineral composition of tella for different preparations [A, B] and formulations [C, $\mathrm{D}] ; \mathrm{G}=$ gesho; $\mathrm{M}=$ moringa; values are least square means with standard errors as error bars and those with different connecting letters are significantly different $(\mathrm{p}<0.05)$.

Table 3. Dietary mineral contents of tella samples as influenced by preparation and formulation

\begin{tabular}{|c|c|c|c|c|c|c|}
\hline \multirow{2}{*}{\multicolumn{7}{|c|}{$\begin{array}{l}\text { Variables } \mathrm{Ln}(\mathrm{mg} / \mathrm{L})^{1} \mathrm{Ca}(\mathrm{mg} / \mathrm{L}) \mathrm{Mg}(\mathrm{mg} / \mathrm{L}) \mathrm{Na}(\mathrm{mg} / \mathrm{L}) \mathrm{K}(\mathrm{mg} / \mathrm{L}) \mathrm{Fe}(\mathrm{mg} / \mathrm{L}) \\
\text { Preparations by formulations }\end{array}$}} \\
\hline & & & & & & \\
\hline Kitta, $100 \% G$ & $1.07^{b}$ & $4.76^{c}$ & $3.17 \mathrm{c}$ & $61.26^{c}$ & $300^{\mathrm{b}}$ & $0.008^{c}$ \\
\hline Kitta, 50:50 G:M & $1.20^{\mathrm{a}}$ & $9.88^{a}$ & $7.21^{\mathrm{a}}$ & $120.67^{a}$ & $320^{a}$ & $0.026^{\mathrm{a}}$ \\
\hline Kitta, $100 \% \mathrm{M}$ & $0.81^{\mathrm{c}}$ & $6.52^{b}$ & $4.31^{b}$ & $100.32^{b}$ & $250^{c}$ & $0.019^{b}$ \\
\hline Enkuro, 100\%G & $1.07^{b}$ & $4.78^{c}$ & $3.16^{c}$ & $61.22^{c}$ & $300^{b}$ & $0.008^{c}$ \\
\hline $\begin{array}{c}\text { Enkuro, 50:50 } \\
\text { G:M }\end{array}$ & $1.20^{\mathrm{a}}$ & $9.96^{\mathrm{a}}$ & $7.15^{\mathrm{a}}$ & $120.67^{a}$ & $320^{a}$ & $0.030^{\mathrm{a}}$ \\
\hline Enkuro, $100 \% \mathrm{M}$ & $0.81^{c}$ & $6.51^{b}$ & $4.31^{b}$ & $100.32^{b}$ & $250^{c}$ & $0.020^{\mathrm{b}}$ \\
\hline SE & 0.011 & 0.041 & 0.0196 & 0.158 & 0.038 & 0.0009 \\
\hline
\end{tabular}

${ }^{1}$ Values are least square means with standard error; $\mathrm{SE}=$ standard error; $\mathrm{G}=$ gesho; $\mathrm{M}=$ moringa; values are least square means with standard errors as error bars and those with different connecting letters are significantly different $(\mathrm{p}<0.05)$.

\subsection{Sensory Acceptability of Tella from Different Preparations and Formulations}

The sensory acceptability of tella samples was significantly influenced by the adjunct preparation methods (color) and formulations (Table 4). Kitta-based tella had higher score for color than the enkuro-based counterpart. The other sensory attributes (aroma, taste and overall acceptability) remained unaffected by adjunct preparation methods.

The formulations also influenced the sensory preference of tella samples. Tella samples made from $100 \%$ gesho and that with $50 \%$ moringa substituting gesho, were better liked in terms of all the sensory attributes considered. The comparatively lower scores of samples with $100 \%$ moringa might be due to the completely new and unfamiliar sensory profiles coming from moringa.

Table 4. Sensory acceptability of tella from the different preparations and formulations 


\begin{tabular}{ccccc}
\hline Variables $^{1}$ & Color & aroma & Taste & OA \\
\hline Preparations & & & & \\
Kitta & $4.477^{\mathrm{a}}$ & $3.82^{\mathrm{a}}$ & $3.75^{\mathrm{a}}$ & $3.92^{\mathrm{a}}$ \\
Enkuro & $4.24^{\mathrm{b}}$ & $3.77^{\mathrm{a}}$ & $3.62^{\mathrm{a}}$ & $3.94^{\mathrm{a}}$ \\
SE & 0.055 & 0.06 & 0.066 & 0.06
\end{tabular}

Formulations

$\begin{array}{ccccc}100 \% \mathrm{G} & 4.38^{\mathrm{ab}} & 4.23^{\mathrm{a}} & 4.07^{\mathrm{a}} & 4.24^{\mathrm{a}} \\ 100 \% \mathrm{M} & 4.46^{\mathrm{a}} & 4.27^{\mathrm{a}} & 4.17^{\mathrm{a}} & 4.33^{\mathrm{a}} \\ 50: 50 \mathrm{G}: \mathrm{M} & 4.23^{\mathrm{b}} & 2.88^{\mathrm{b}} & 2.80^{\mathrm{b}} & 3.22^{\mathrm{b}} \\ \text { SE } & 0.067 & 0.073 & 0.080 & 0.073\end{array}$

Preparations by formulations

\begin{tabular}{ccccc} 
Kitta, $100 \% \mathrm{M}$ & $4.53 \mathrm{a}$ & $4.30^{\mathrm{a}}$ & $4.05^{\mathrm{a}}$ & $4.07^{\mathrm{a}}$ \\
Kitta, 50:50 G:M & $4.23^{\mathrm{ab}}$ & $4.16^{\mathrm{a}}$ & $4.086^{\mathrm{a}}$ & $4.41^{\mathrm{a}}$ \\
Kitta, $100 \% \mathrm{M}$ & $4.55 \mathrm{a}$ & $4.35^{\mathrm{a}}$ & $4.41^{\mathrm{a}}$ & $4.41^{\mathrm{a}}$ \\
Enkuro, $100 \% \mathrm{G}$ & $4.37^{\mathrm{ab}}$ & $4.20^{\mathrm{a}}$ & $3.94^{\mathrm{a}}$ & $4.23^{\mathrm{a}}$ \\
Enkuro, 50:50 G:M & $4.34^{\mathrm{ab}}$ & $2.81^{\mathrm{b}}$ & $2.79^{\mathrm{b}}$ & $3.27^{\mathrm{b}}$ \\
Enkuro, $100 \% \mathrm{M}$ & $4.12^{\mathrm{b}}$ & $2.96^{\mathrm{b}}$ & $2.82^{\mathrm{b}}$ & $3.16^{\mathrm{b}}$ \\
SE & 0.099 & 0.11 & 0.11858044 & 0.11 \\
\hline
\end{tabular}

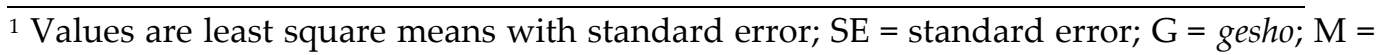
moringa; values are least square means with standard errors as error bars and those with different connecting letters are significantly different $(p<0.05)$.

Looking at the interactions of preparation methods and formulations, kitta-based tella with 100 gesho (traditional control) and $50 \%$ substituted by moringa had better preference than the rest although there was no clear statistical segregation. The general evaluation of the tella samples was that all samples were liked by consumers with the scores for overall acceptability ranging from 3.16 to 4.41 . The overall average scores of all the tested sensory parameters were 3.94 on the scale of 5 , with being the best (like extremely) and 1 being poorest (dislike extremely).

\section{Discussion}

The dynamics in the biochemical properties indicated that the addition of moringa play important nutritional roles (micronutrients [8-10]) and also suppresses yeast activities and promotes $\mathrm{LAB}$, which, coupled with the culture of consuming tella unheated after fermentation, creates opportunity for probiotic application. Further investigations into the nutritional and health beneficial potentials of tella and many other indigenous African and Asian foods may present a great opportunity in human nutrition and health.

The drops in the yeast count and the $\mathrm{pH}$ of the product, as well as the accumulation of the TA, were likely due to other factor such as the depletion of the fermentable carbohydrates and the inhibitory effects of the acid and alcohol levels. The drop in $\mathrm{pH}$ from 5.31 for the $100 \%$ gesho formulation on the first day to below 4.50 for the $50 \%$ and $100 \%$ moringa incorporated samples indicates that the product is in a $\mathrm{pH}$ condition unfavorable for many pathogenic organisms, presenting an additional technical functionality to the product in addition to its micronutrient and probiotic potential. The decreasing trend of yeast count over the fermentation and storage times was faster in the present study than those reported previously [13].

The dietary mineral results from the current research are generally, promising as a means of nutritional intervention in communities with significant practices of tella consumption. The result also presented a great lesson of dietary interventions for addressing micronutrient deficiencies of the Ethiopian populations residing in the central and northern parts of the country, which makes up the vast majority of the Orthodox Christians, often falling short of micronutrient intakes due to recurrent fasting practices [18]. 
The sensory analysis result implies that substitution of gesho (a less nutritious, at least not well characterized), with moringa that is well characterized crop and reportedly superior nutritionally can be a sound and acceptable strategy as local dietary intervention in areas with micronutrient challenges in Ethiopia. The research also documented lessons to improve the nutritional and probiotic functionalities of popular indigenous diets in African and elsewhere.

\section{Conclusions}

The substation of gesho with a more nutritious leaves of moringa resulted in products of higher nutritional contents (micronutrients). The substation of gesho with moringa also suppressed the activities and counts of yeast cells, suppressing alcohol production and favoring $\mathrm{LAB}$ activities and lactic acid production. This enhanced the probiotic potential of tella, leaving it appealing to the nutrition of adults in central and northern Ethiopia. A $50 \%$ substation of gesho with moringa resulted in tella of higher nutritional (dietary minerals) and sensory acceptability.

Author Contributions: Mr. AMB initiated the proposal in consultation with the other two and collected the data; Dr. TFT analyzed the data with Mr. AMB and wrote the manuscript text and contributed to the graphics; Mr. TBL contributed in shaping the proposal and edited the final write up.

Funding: This research was funded by the Addis Ababa Education Department and Nifas Silk Polytechnic College, in support of AMB as a graduate student at Hawassa University.

Data Availability Statement: The data presented in this study are available on request to authors.

Informed Consent Statement: Informed consent was obtained from all sensory panelists involved in the study.

Acknowledgments: Technical supports provided the authors by lab staffs of the School of Nutrition, Food Science and Technology at Hawassa University. The professional support by Mr. Yassin Hassen is of special consideration in the microbial analysis.

Conflicts of Interest: The authors declare no conflict of interest.

\section{References}

1. Berhanu, A. Microbial profile of Tella and the role of gesho (Rhamnus prinoides) as bittering and antimicrobial agent in traditional Tella (Beer) production.; 2014; Vol. 21;

2. Lee, M.; Regu, M.; Seleshe, S. Uniqueness of Ethiopian traditional alcoholic beverage of plant origin, tella. J. Ethn. Foods 2015, 2, 110-114, doi:10.1016/j.jef.2015.08.002.

3. Abawari, R.A. Microbiology of Keribo fermentation: An Ethiopian traditional fermented beverage. Pakistan J. Biol. Sci. 2013, 16, 1113-1121, doi:10.3923/pjbs.2013.1113.1121.

4. Hotessa, N.; Robe, J. Ethiopian Indigenous Traditional Fermented Beverage: The Role of the Microorganisms toward Nutritional and Safety Value of Fermented Beverage. Int. J. Microbiol. 2020, 2020.

5. Tekle, B.; Anuradha Jabasingh, S.; Fantaw, D.; Gebreslassie, T.; Ram Mohan Rao, S.; Baraki, H.; Gebregziabher, K. An insight into the Ethiopian traditional alcoholic beverage: Tella processing, fermentation kinetics, microbial profiling and nutrient analysis. LWT 2019, 107, 9-15, doi:10.1016/j.lwt.2019.02.080.

6. Mulaw, G.; Muleta, D.; Tesfaye, A.; Sisay, T. Protective Effect of Potential Probiotic Strains from Fermented Ethiopian Food against Salmonella Typhimurium DT104 in Mice. Int. J. Microbiol. 2020, 2020, doi:10.1155/2020/7523629.

7. Wedajo Lemi, B. Microbiology of Ethiopian Traditionally Fermented Beverages and Condiments. Int. J. Microbiol. 2020, 2020.

8. Olson, M.E.; Sankaran, R.P.; Fahey, J.W.; Grusak, M.A.; Odee, D.; Nouman, W. Leaf protein and mineral concentrations across the "Miracle tree" genus moringa. PLoS One 2016, 11, doi:10.1371/journal.pone.0159782.

9. Gopalakrishnan, L.; Doriya, K.; Kumar, D.S. Moringa oleifera: A review on nutritive importance and its medicinal application. Food Sci. Hum. Wellness 2016, 5, 49-56. 
10. Kumssa, D.B.; Joy, E.J.M.; Young, S.D.; Odee, D.W.; Ander, E.L.; Broadley, M.R. Variation in the mineral element concentration of Moringa oleifera Lam. and M. stenopetala (Bak. f.) Cuf.: Role in human nutrition. PLoS One 2017, 12, e0175503, doi:10.1371/journal.pone.0175503.

11. Teferra, T.F.; Kurabachew, H.; Tadesse, T.F.; Nigusse, G. Nutritional, Microbial and Sensory Properties of Flat-bread (kitta) Prepared from Blends of Maize (Zea mays L.) and Orange-fleshed Sweet Potato (Ipomoea batatas L.) Flours Fabrication of Iron and ascorbic acid Nanocomposite View project Nutritional, Micro. Int. J. Food Sci. Nutr. Eng. 2015, 2015, 33-39.

12. Fentie, E.G.; Emire, S.A.; Demsash, H.D.; Dadi, D.W.; Shin, J.-H. Cereal- and Fruit-Based Ethiopian Traditional Fermented Alcoholic Beverages. Foods 2020, Vol. 9, Page 1781 2020, 9, 1781, doi:10.3390/FOODS9121781.

13. Andualem, B.; Shiferaw, M.; Berhane, N. Isolation and characterization of Saccaromyces cervisiae yeasts isolates from "tella" for beer production. Annu. Res. Rev. Biol. 2017, 15, 1-12, doi:10.9734/ARRB/2017/34129.

14. Tafere, G. A review on Traditional Fermented Beverages of Ethiopian. J. Nat. Sci. Res. www 2015, 5, $2225-921$.

15. Spedding, G. Alcohol and Its Measurement. In Brewing Materials and Processes: A Practical Approach to Beer Excellence; Elsevier Inc., 2016; pp. 123-149 ISBN 9780128004685.

16. de Jesus Filho, M.; do Carmo, L.B.; Della Lucia, S.M.; Saraiva, S.H.; Costa, A.V.; Osório, V.M.; Teixeira, L.J.Q. Banana liqueur: Optimization of the alcohol and sugar contents, sensory profile and analysis of volatile compounds. LWT 2018, 97, 31-38, doi:10.1016/j.lwt.2018.06.044.

17. Zheng, Y.; Du, J.; Li, M. Haze-active protein and turbidity in commercial barley and wheat beers at different storage temperatures. Int. Food Res. J. 2020, 27, 295-307.

18. Desalegn, B.B.; Lambert, C.; Riedel, S.; Negese, T.; Biesalski, H.K. Ethiopian orthodox fasting and lactating mothers: Longitudinal study on dietary pattern and nutritional status in rural tigray, Ethiopia. Int. J. Environ. Res. Public Health 2018, 15, 1767, doi:10.3390/ijerph15081767. 